\title{
Development of High Performance Temperature Controlled Laboratory-Based Diffusivity Device
}

\author{
Ikhazuangbe $^{1}$ P.M.O., Eruoto ${ }^{2}$ M.O. \\ ${ }^{1}$ Federal University of Technology, Chemical engineering department, Owerri, Nigeria \\ ${ }^{2}$ Western Delta University, Physics with electronics department, Oghara, Nigeria
}

\begin{abstract}
A laboratory-based device for high performance diffusivity of fluid-air was developed. Acetone-air was used for the development at $30^{\circ} \mathrm{C}$ and a total pressure of $1.2 \mathrm{~atm}$. The volume of the containing cylinder for acetone was obtained $90 \mathrm{~cm}^{3}$. Height and diameter of the cylinder was 20 and $2.4 \mathrm{~cm}$ respectively. The level change of diffusion of the acetone after 10,20,30, 40, 50 and 60 minutes are 0.4, 0.57, 0.7, 0.8, 0.9 and 0.99cm respectively. The specific speed of the blower at the stated conditions is $=30.3 \mathrm{rpm}$, area of the piston in the blower $=4.52 \mathrm{~cm}^{2}$, discharge capacity of blower $=0.0023 \mathrm{~m}^{3} / \mathrm{min}$ and the horse power of the blower is $=$ $0.0774 \mathrm{~J} / \mathrm{min}$. The values obtained from each of the design unit of the development shows that the device will produce reliable result when used for experiment.
\end{abstract}

Keywords: Acetone, Blower, cylinder, diffusivity; fluid

\section{INTRODUCTION}

The diffusivity of a substance is a property of that substance which gives a measure of its diffusive mobility under a given condition. It is dependent on temperature, pressure, concentration and the nature of other substances around (Inyiama, 2006). In general, diffusivities of gases increase with increasing temperature but decrease with increasing pressure. Liquid and solid diffusivities also increase with increasing temperature. Also, while the effect of concentration of gas diffusivities is minimal at low densities, liquid and solid diffusivities are strongly concentration dependent (Iyagba, 2008). For gases, the diffusivities coefficients can be determined experimentally, calculated from equations developed from the kinetic theory or computed by use of some empirical relations (Inyiama, 2006). The kinetic theory of gases provides a means of visualizing the diffusional processes. In a simplified treatment of diffusion using the kinetic theory approach, a molecule is imagined to travel in a straight line at a uniform velocity until collision with another molecule alters its velocity both in magnitude and direction. The molecules move at high velocities but the distance before collision is extremely short. The average distance the molecule travels before collision is its mean free path while the average velocity depends on temperature. The molecular movement is thus highly zigzag and the net distance in one direction which the molecule moves in a given time, that is, the rate of diffusion, is only a small fraction of its actual path. Consequently, the rate of diffusion is slow, although it is inversely proportional to pressure and directly proportional to temperature (Chukwuma, 2007).

In this work, the diffusivity coefficient of acetone vapor in air will be used for the development of high performance laboratory-based diffusivity device.

Theory

The experimental value of the diffusivity of air-acetone $\left(\mathrm{D}_{\mathrm{AB}}\right)$ at low pressures at $20^{\circ} \mathrm{C}$ is $1.2 \times 10^{-}$ ${ }^{5} \mathrm{~m}^{2} / \mathrm{s}$ (Chukwuma, 2007).

The general diffusion equation is given as:

$\mathrm{N}_{\mathrm{A}}=\left(\mathrm{N}_{\mathrm{A}}+\mathrm{N}_{\mathrm{B}}\right) X \mathrm{~A}-\mathrm{CD}_{\mathrm{AB}} \frac{d X_{A}}{d Z}$

Where $\mathrm{N}_{\mathrm{A}}, \mathrm{N}_{\mathrm{B}}=$ the molar fluxes of $\mathrm{A}$ and $\mathrm{B}$ respectively about a fixed axes, $\mathrm{X}_{\mathrm{A}}=$ the molar fraction of $\mathrm{A}$ in liquid phase, $\mathrm{D}_{\mathrm{AB}}=$ diffusivity of $\mathrm{A}$ in $\mathrm{B}, \mathrm{C}=$ total concentration of mixture, $\mathrm{Z}=$ direction of diffusion process. 
Since $\mathrm{B}$ is stagnant, $\mathrm{N}_{\mathrm{B}}=0$, hence equation 1 becomes

$\mathrm{N}_{\mathrm{A}}=\mathrm{N}_{\mathrm{A}} \mathrm{X}_{\mathrm{A}}-\mathrm{CD}_{\mathrm{AB}} \frac{d X_{A}}{d Z}$

- $\quad \mathrm{CD}_{\mathrm{AB}} \frac{d X_{A}}{d Z}=\left(\mathrm{N}_{\mathrm{A}}-\mathrm{X}_{\mathrm{A}}\right)$

$\mathrm{dZ}=\frac{-C D_{A B} d X_{A}}{N_{A}\left(1-X_{A}\right)}$

$\int_{0}^{1} d Z=-\frac{C D_{A B}}{N_{A}} \int_{X_{A S}}^{X_{A}} \frac{d X_{A}}{\left(1-X_{A}\right)}$

$\mathrm{N}_{\mathrm{A}}=-\frac{C D_{A B}}{Z} \ln \frac{\left(1-X_{A S}\right)}{\left(1-X_{A}\right)}$

Where $\mathrm{X}_{\mathrm{AS}}=$ mole fraction of $\mathrm{A}$ at the interphase, $\mathrm{X}_{\mathrm{A}}=$ mole fraction of component $\mathrm{A}$ in the bulk flow.

Equation 2 holds if the mass transfer resistance is in the liquid phase. But in this work, the vaporization of acetone is rapid, thus, the resistance to mass transfer is in the gas phase. Therefore, equation 2 has to be in terms of mole fraction in the gas phase, thus equation 2 becomes

$\mathrm{N}_{\mathrm{A}}=-\frac{C D_{A B}}{Z} \ln \frac{\left(1-Y_{A S}\right)}{\left(1-Y_{A}\right)}$

Assuming ideal gas behavior

$\mathrm{C}=\mathrm{P} / \mathrm{RT}$

But $\mathrm{Y}_{\mathrm{B} 2}=\mathrm{P}_{\mathrm{B} 2} / \mathrm{P}$ hence $1-\mathrm{Y}_{\mathrm{B} 2}=\frac{P-P_{B 2}}{P}, \mathrm{Y}_{\mathrm{A} 1}=\mathrm{P}_{\mathrm{A} 1} / \mathrm{P}$ and $1-\mathrm{Y}_{\mathrm{A} 1}=\frac{P-P_{A 1}}{P}$

Substituting in equation 3 gives

$\mathrm{N}_{\mathrm{A}}=-\frac{P D_{A B}}{R T Z} \ln \frac{P-P_{B 2}}{P-P_{B 1}}$

Where $\mathrm{P}$ total pressure, $\mathrm{P}_{\mathrm{B} 2}=$ partial pressure of air at point $2, \mathrm{P}_{\mathrm{A} 1}=$ partial pressure of acetone the bulk flow (point 1).

Now $\mathrm{P}-\mathrm{P}_{\mathrm{A} 2}=\mathrm{P}_{\mathrm{B} 2}=$ partial pressure of component of air at the point 2 .

$\mathrm{P}-\mathrm{P}_{\mathrm{A} 1}=\mathrm{P}_{\mathrm{B} 1}$

Equation 4 becomes

$\mathrm{N}_{\mathrm{A}}=\frac{D_{A B}}{R T Z} \mathrm{P} \ln \frac{P_{B 2}}{P_{B 1}}$

In $\rho$ and $\mathrm{M}$ are the respective density and molecular weight of the liquid and $\mathrm{A}$ the cross sectional area of the tube, the amount of liquid in the tube at any instant $=\rho M\left(\frac{h-x}{M}\right)$ moles.

Rate of evaporation of the $=\frac{d \rho A \frac{(h-x)}{M}}{d t}=\frac{-\rho A}{M} \frac{d Z}{d t}$

Rate of evaporation per unit area $=\frac{-\rho}{M} \frac{d Z}{d t}$

Equating 5 and 6

$\frac{-\rho}{M} \frac{d Z}{d t}=\frac{D_{A B}}{R T Z} \mathrm{P} \ln \frac{P_{B 2}}{P_{B 1}}$

Or $\mathrm{ZdZ}=\left[\frac{D_{A B}}{R T \rho} \mathrm{PM} \ln \frac{P_{A S}}{P_{B}}\right] \mathrm{dt}$

i.e $\mathrm{ZdZ}=\mathrm{Kdt}$

Where $\mathrm{K}=\frac{D_{A B}}{R T \rho} \mathrm{PM} \frac{\left(P_{B 2}-P_{B 1}\right)}{\left(\mathrm{P}_{\mathrm{B}}\right) \ln }$

Where $\left(\mathrm{P}_{\mathrm{B}}\right) \ln =\frac{\left(P_{B 2}-P_{B 1}\right)}{\ln \left(P^{B 2} / P_{B 1}\right)}$

at $\mathrm{t}=0, \mathrm{Z}=\mathrm{Z}_{\mathrm{o}}$, and at $\mathrm{t}=\mathrm{t}, \mathrm{Z}=\mathrm{Z}$

Upon integration, we have

$\int_{Z_{o}}^{Z} Z d Z=\mathrm{K} \int_{0}^{t} d t=\mathrm{Kt}=\frac{Z^{2}-Z_{0}^{2}}{2}$ 
$\left(\mathrm{Z}-\mathrm{Z}_{\mathrm{o}}\right)\left(\mathrm{Z}-\mathrm{Z}_{\mathrm{o}}+2 \mathrm{Z}_{\mathrm{o}}\right)=2 \mathrm{Kt}$

$\frac{t}{Z-Z_{o}}=\frac{Z-Z_{o}}{2 K}+\frac{Z_{o}}{K}$

Basis: $1 \mathrm{~min}$

At $30^{\circ} \mathrm{C}, \mathrm{T}=303 \mathrm{~K}$

Using Antoine equation,

$\mathrm{P}_{\mathrm{A} 1}=282 \mathrm{mmHg}=0.371 \mathrm{~atm} \mathrm{P}_{\mathrm{A} 2}=0.0$

$\mathrm{P}_{\mathrm{B} 1}=1-\mathrm{P}_{\mathrm{A} 1}=0.629 \mathrm{~atm}, \mathrm{P}_{\mathrm{B} 2}=1 \mathrm{~atm}$

$\left(\mathrm{P}_{\mathrm{B}}\right) \ln =\frac{\left(P_{B 2}-P_{B 1}\right)}{\ln \left(e^{\left.P_{B 2} / P_{B 1}\right)}\right.}=\frac{(1-0.629)}{\ln (1 / 0.629)}=\frac{0.371}{\ln 1.5898}=0.8$

$\therefore \mathrm{K}=\frac{0.12 \frac{\mathrm{cm}^{2}}{\mathrm{~s}} \times 1 \mathrm{~atm} \times \frac{58.08 \mathrm{~g}}{\mathrm{~mol}}}{82.057 \frac{\mathrm{cm} 3 \mathrm{~atm}}{\mathrm{gmol}-\mathrm{K}} \times 303 \mathrm{~K} \times 0.79 \mathrm{~g} / \mathrm{cm}^{3}} \times \frac{(1-0.629)}{0.8}$

$\mathrm{K}=1.646 \times 10^{-4} \mathrm{~cm}^{2} / \mathrm{s}$

Also, Density $=\frac{\text { mass }}{\text { volume }}$

Equipment design

Volume of a cylinder $=\pi \mathrm{r}^{2} \mathrm{~h}$

Mass of acetone $=58.08 \mathrm{~g} / \mathrm{mol}$

Density of acetone $=0.79 \mathrm{~g} / \mathrm{cm}^{3}$

For one mole of acetone

Mass of acetone $=58.08 \mathrm{~g}$

Volume of acetone $=\frac{58.08}{0.79}=74 \mathrm{~cm}^{3}$

At $\mathrm{t}=0, \mathrm{Z}_{\mathrm{o}}=0$,

At $\mathrm{t}=10 \mathrm{~min}$, from equation 8 ,

$\mathrm{Z}=0.44 \mathrm{~cm}$

Table1: Diffusivity change dependency on time

\begin{tabular}{|c|c|}
\hline T $(\mathbf{m i n})$ & $\mathbf{Z}(\mathbf{c m})$ \\
\hline 0 & 0 \\
\hline 10 & 0.44 \\
\hline 20 & 0.63 \\
\hline 30 & 0.78 \\
\hline 40 & 0.89 \\
\hline 50 & 0.99 \\
\hline 60 & 1.09 \\
\hline
\end{tabular}

Since volume of a cylinder $=\pi r^{2} h$

Safety allowance $(20 \%)=20 / 100 \times 74=14.8 \mathrm{~cm}^{3}$

Volume of the cylinder $=$ volume of acetone + safety allowance

$90 \mathrm{~cm}^{3}=\pi \mathrm{r}^{2} \mathrm{~h}$

For a cylindrical height of $20 \mathrm{~cm}$

$90 \mathrm{~cm}^{3}=\pi \times \mathrm{r}^{2} \times 20 \mathrm{~cm}$

$\mathrm{r}^{2}=\frac{90 \mathrm{~cm}^{2}}{\pi \times 20}$

$\mathrm{r}=\sqrt{1.4324}$ 
Ikhazuangbe P.M.O. \& Eruoto M.O.

$=1.2 \mathrm{~cm}$

Diameter of the cylinder $=2.4 \mathrm{~cm}$

\section{BLOWER}

Internal diameter of piston $=2.4 \mathrm{~cm}$

Length of piston $=10 \mathrm{~cm}$

Efficiency of the blower $=75 \%$

Number of strokes of the piston $=50 / \mathrm{min}$

Area of piston, $\mathrm{a}=\frac{\pi d^{2}}{4}=4.52 \mathrm{~cm}^{2}$

Volume swept by piston $=$ area of piston $\mathrm{x}$ length of piston $=4.52 \mathrm{~cm}^{2} \times 10 \mathrm{~cm}=45.2 \mathrm{~cm}^{3}$

Discharge capacity $\mathrm{Q}=$ volume swept by piston $\mathrm{x}$ number of strokes $=45.2 \mathrm{~cm}^{3} \times 50 / \mathrm{min}=$ $2260 \mathrm{~cm}^{3} / \mathrm{min}=0.0023 \mathrm{~m}^{3} / \mathrm{min}$

Speed of the blower

$\mathrm{Ns}=\frac{N Q^{1 / 2}}{H^{3 / 4}}$

Where Ns = specific speed, $\mathrm{rpm}, \mathrm{N}=$ pump speed, $\mathrm{rpm}, \mathrm{Q}=$ air discharge $\mathrm{m}^{3} / \mathrm{s}, \mathrm{H}=$ total head, $\mathrm{m}$

$\mathrm{N}=540 \mathrm{rpm}$

$\mathrm{H}=1.2 \mathrm{~atm}=12.40 \mathrm{~m}$

$\mathrm{Q}=0.138 \mathrm{~m}^{3} / \mathrm{s}$

$\therefore \mathrm{Ns}=\frac{540 \times 0.138^{0.5}}{12.4^{3 / 4}}=\frac{200.6}{6.61}=30.3 \mathrm{rpm}$

Total head $=1.2 \mathrm{~atm}$

Force required to work the piston during $=\frac{\text { Total head } x \text { area of piston }}{\text { efficiency of piston }}$

$=\frac{12000 \mathrm{kgf} / \mathrm{m}^{2} \times 0.00045 \mathrm{~m}^{2}}{0.75}=7.2 \mathrm{kgf}$

Horse power $($ H.P $)=\frac{\text { Total } x \text { distance moved } x \text { number of strokes } / \mathrm{min}}{4560}$

$=\frac{7.2 \mathrm{kgf} \times 0.1 \mathrm{~m} \times 50 / \mathrm{min}}{4560}$

$=0.0079 \frac{\mathrm{kgf} \cdot \mathrm{m}}{\min }$

$=0.0079 \frac{\mathrm{kgf} . \mathrm{m}}{\min } \times 9.8067 \frac{\mathrm{J}}{\mathrm{kgf} . \mathrm{m}}$

$=0.0774 \mathrm{~J} / \mathrm{min}$

\section{DESIGN SSUMmary}

\begin{tabular}{|l|l|}
\hline Cylinder & \\
\hline Volume of the cylinder & $90 \mathrm{~cm}^{3}$ \\
\hline Height of cylinder & $20 \mathrm{~cm}$ \\
\hline Diameter of cylinder & $2.4 \mathrm{~cm}$ \\
\hline Blower & Centrifugal type \\
\hline Length of piston & $10 \mathrm{~cm}$ \\
\hline Area of piston & $4.52 \mathrm{~cm}^{2}$ \\
\hline Volume swept by piston & $45.2 \mathrm{~cm}^{3}$ \\
\hline Discharge capacity of blower & $0.0023 \mathrm{~m}^{3} / \mathrm{min}$ \\
\hline Speed of the blower & $30.3 \mathrm{rpm}$ \\
\hline Force required to work the piston & $7.2 \mathrm{kgf}$ \\
\hline Horse power of the blower & $0.0774 \mathrm{~J} / \mathrm{min}$ \\
\hline
\end{tabular}




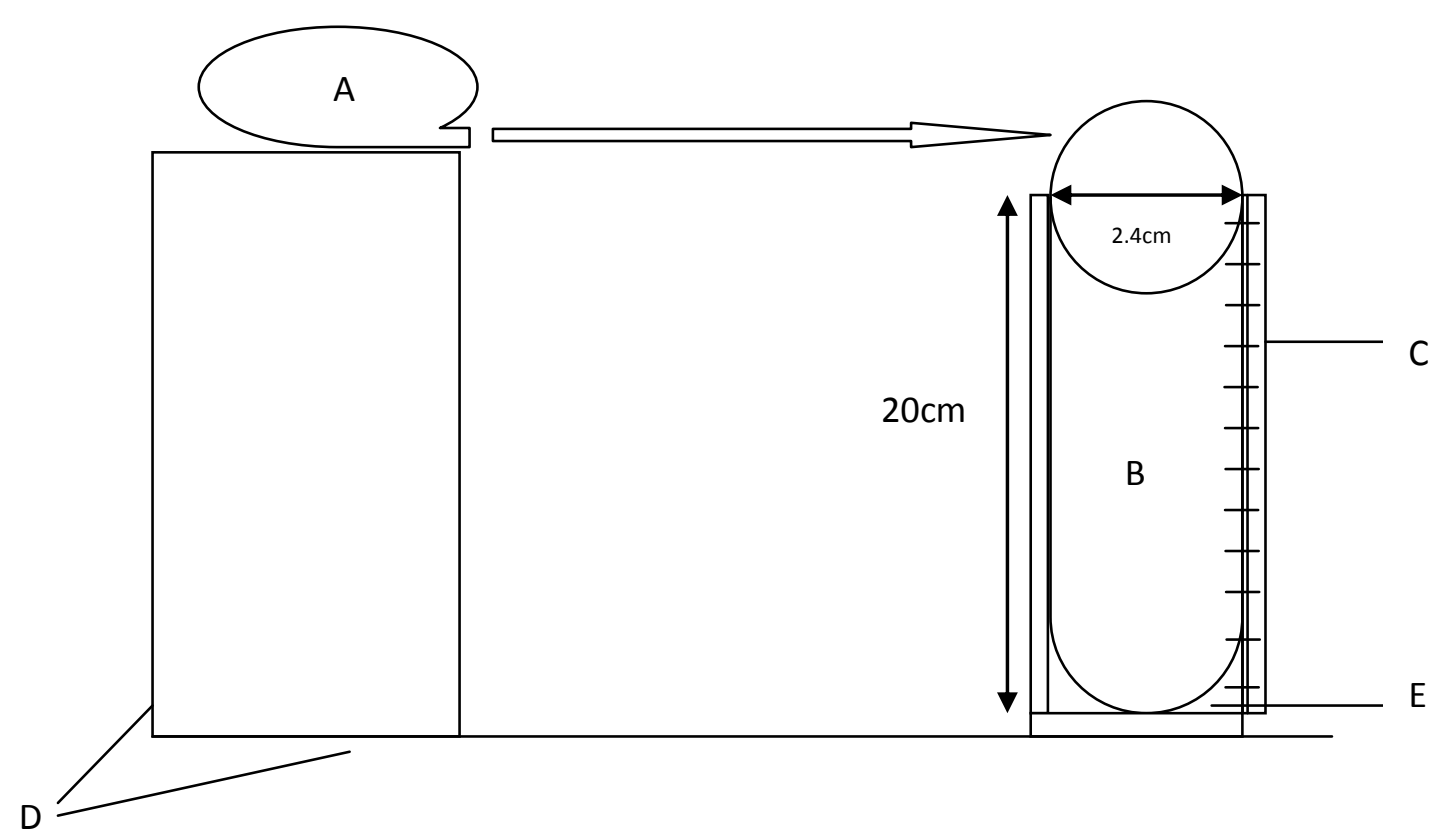

Fig1. Pictorial diagram of the device

$\mathrm{A}=$ blower, $\mathrm{B}=$ cylinder, $\mathrm{C}=$ calibrated cylinder and $\mathrm{D}=$ stand, $\mathrm{E}=$ Plastic thermostatic water bath

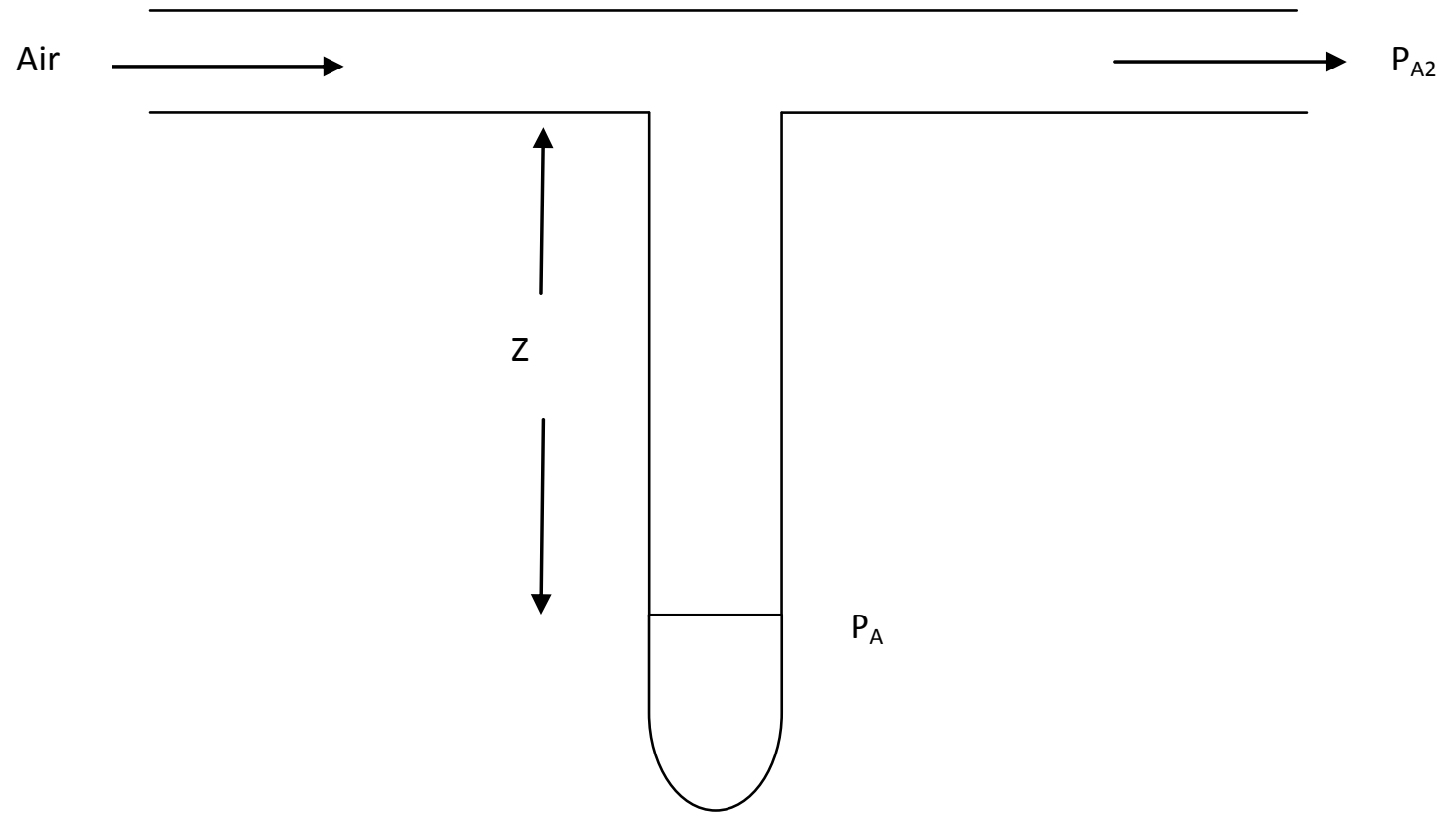

Fig2. Determination of diffusivity

\section{DisCUSSION}

The device developed uses centrifugal type of blower, which has a speed of $30.3 \mathrm{rpm}$ with a discharge capacity of $0.0023 \mathrm{~m}^{3} / \mathrm{min}$.

The developed calibrated cylinder inserted in a temperature controlled transparent plastic water bath has values which are reasonable in the laboratory contest as its volume and dimensions.

The diffusivity of air-acetone used for the development gives good diffusion interval at the corresponding time. When this device is used to carry out experiment in the laboratory, the results will give impressive graph when time is plotted against diffusion interval, using equations 7 and 9 , from which the diffusivity can be obtained. 


\section{Conclusion}

This device developed can be used to perform chemical engineering laboratory experiment, from which values obtained will be used for the determination of the diffusivity of acetone-air or diffusivity of any other light liquid in air at different temperature.

\section{ACKNOWLEDGEMENT}

The authors sincerely acknowledge Mr. Ikhazuangbe Benson T of NNPC-PPMC, Aviele pump station, for his financial assistance.

\section{REFERENCES}

[1]Chukwuma, F.O. (2007), Separation processes, M\&J orbit communications ltd, PH, Nigeria, $1^{\text {st }}$ edition. Pg. 37, 50

[2] Inyiama, F.C. (2006), Fundamentals of chemical engineering practicals, Hugotez publications, Enugu, Nigeria. Pg. $102-105$.

[3]Iyagba, E.T. (2008), fundamentals of transport phenomena, Jita enterprises Nig. Ltd, PH, Nigeria. Pg.28.

\section{AUTHORS' BIOGRAPHY}

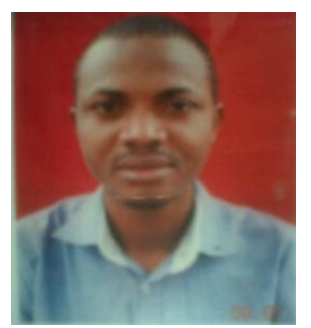

P.M.O. Ikhazuangbe's area of specialization are Chemical and environmental engineering, separation processes, process and equipment design, transport phenomena and reaction engineering. He was a researcher in Madonna University, Akpugo, Nigeria and a visiting researcher to Delta State University, Oleh, Nigeria. His research articles numbering 12 with several citations. He is a member of Nigeria Society of Chemical engineers.

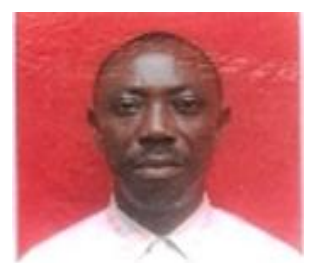

Eruotor Moses Ogheneruona, is an Assistant Lecturer, in the Department of Physics with Electronics, Western Delta University, Oghara, Delta State, Nigeria. He has 3 publications with interest in design and production engineering. 